\title{
Q ualidade de esterco de ave poedeira submetido a dois tipos de tratamentos de compostagem ${ }^{1}$
}

\author{
Fabiano G. dos Santos ${ }^{2}$; Pedro A. V. Escosteguy ${ }^{3}$ \& Laura B. Rodrigues ${ }^{3}$
}

\begin{abstract}
RESUMO
Neste trabal ho se avaliou a qualidade de compostos de esterco de ave poedeira produzidos em pilhas de compostagem e se testaram os seguintes tratamentos: 1) sem gesso e sem revolvimento; 2) com gesso e sem revolvimento; 3) sem gesso e com revolvimento e 4) com gesso e com revolvimento. Para avaliar a qualidade dos compostos foram considerados os padrões do Ministério de A gricultura, Pecuária e A bastecimento (MAPA), estabelecidos para ovos e larvas de helmintos, Sal monella sp, coliformes totais e fecais, $\mathrm{Cd}, \mathrm{Cr}, \mathrm{Ni}, \mathrm{Pb}, \mathrm{Se}, \mathrm{C}, \mathrm{N}$, umidade, relações $\mathrm{C}: \mathrm{N}, \mathrm{C}: \mathrm{CTC}$ (Capacidade de troca de cátions) e pH. Os compostos obtidos nas pilhas revolvidas atenderam aos padrões de qualidade, exceto 0 teor de $C$, que foi menor. N os compostos das pilhas com gesso e não revolvidas, o teor deste elemento excedeu o mínimo exigido mas os valores de $\mathrm{N}$, de ovos de helmintos e de umidade, não corresponderam ao padrão do M APA. Os teores de metais e de Se dos compostos foram menores que o máximo permitido, exceto 0 de $C d$, cujo teor foi elevado no esterco utilizado nas pilhas sem gesso. Este aditivo decresceu o valor do pH dos compostos e aumentou o teor de $\mathrm{N}$ das pilhas não revolvidas. Em relação a todos os atributos avaliados, os melhores compostos foram obtidos nas pilhas revolvidas.
\end{abstract}

Palavras-chave: fertilizante orgânico, enteropatogênicos, parasitos, metais tóxicos

\section{Q uality of poultry manure submitted to two types of composting treatments}

\begin{abstract}
The quality of poultry manure composts obtained from composting heaps were evaluated, in the following treatments: 1) without gypsum and turning; 2) without gypsum and with turning; 3) with gypsum and turning; 4) with gypsum and without turning. The quality of composts was evaluated with the Department of Agricultural (DA) standards established to the occurrence of eggs and grubs of helminthes, Salmonella sp, fecal and total coliforms, $\mathrm{Cd}, \mathrm{Cr}, \mathrm{Ni}, \mathrm{Pb}, \mathrm{Se}, \mathrm{C}, \mathrm{N}$, humidity, C:N and $\mathrm{C}: \mathrm{CEC}$ rations, and $\mathrm{pH}$. The quality of composts from the turned heaps agrees with the DA standards, except the $\mathrm{C}$ content, which was lower. In the composts obtained from heaps with gypsum addition and without turner, the content of this element was higher than the minimum required but the values of $\mathrm{N}$, eggs of helminthes, and water content did not meet the DA standards. The metal content of the composts was low, with the exception of $\mathrm{Cd}$, but it was due to the high content of this metal in the manure used to make the gypsum heaps. This additive decreased the $\mathrm{pH}$ value of the composts and increased the $\mathrm{N}$ content of the no turned heaps. Considering all evaluated attributes, the best composts were obtained from the turned heaps.
\end{abstract}

Key words: organic fertilizer, enteropatogenic, parasites, toxic metals

${ }^{1}$ Parte da Dissertação de Mestrado do primeiro autor apresentada à UPF, financiado pela FAPERGS

2 Mestre em Engenharia. E-mail: fgoellner@bol.com.br

${ }^{3}$ UPF. CP 611, CEP 99001-970 Passo Fundo, RS. E-mail: escosteguy@upf.br; laurab@upf.br 


\section{INTRODUÇÃO}

O plantel de aves poedeiras no Brasil foi de 93.206.329/ mês, em 2006 (UBA, 2007). Considerando-se que 100.000 poedeiras geram cerca de $12 \mathrm{t} \mathrm{dia}{ }^{-1}$ de esterco (Moreng \& Avens, 1990), estima-se que cerca de $11.185 \mathrm{t} \mathrm{dia}^{-1}$ deste resíduo são gerados no País. O esterco de ave poedeira criada em sistema de confinamento tem sido aplicado em solos agrícolas, pois é considerada fonte importante de nutrientes vegetais, devido a alimentação dessas aves se constituir de rações com alto teor de proteína (Kiehl, 2002). Conforme o autor, a baixa relação carbono: nitrogênio deste esterco favorece a disponibilidade da maior parte dos nutrientes às culturas agrícolas, em especial do nitrogênio aspecto que, juntamente com o baixo custo do esterco, tem motivado a aplicação deste resíduo em solos agrícolas (Kiani et al., 2005; Endale et al., 2008), apesar de ter sido efetuado, também, sem o tratamento prévio do referido esterco. Por outro lado, são desconhecidos os impactos ambientais desta prática em detrimento do uso do esterco tratado.

Em sistemas orgânicos de produção, a adubação com estercos obtidos de outros sistemas pressupõe a compostagem e a bioestabilização do resíduo (Brasil, 2008). Em adição, resultados de pesquisas relatam que a aplicação de esterco de suínos, bovinos e de ave de corte em desconformidade com as recomendações técnicas, podem contaminar o solo e os corpos hídricos (Hsu \& Lo, 2001; Ceretta et al., 2003; Palhares \& Calijuri, 2007) e a atmosfera (Sommer et al., 2007).

Por sua vez, a compostagem produz um fertilizante orgânico mais estável e em melhores condições sanitárias que o esterco (Tiquia et al., 1998; Vinnerás, 2007; Gonçalves \& Marin, 2007). Este processo pode ser uma alternativa viável para o tratamento do esterco de ave poedeira, pois, em geral, é de baixo custo e impacto ambiental (Lima et al., 2009). Para o desenvolvimento adequado da compostagem é necessário controlar alguns fatores, como o teor de água e de ar (oxigênio), além da temperatura (Lau et al., 1992; Tiquia et al., 1998; Fernandes \& Souza, 2001; Corrêa et al., 2008). Adicionalmente, a qualidade do composto produzido pode ser melhorada com a adição de aditivos que valorizem o composto para fins de uso agrícola. Resultados de pesquisa sugerem que o gesso pode ser um desses aditivos visto que decresce a perda de $\mathrm{N}$ na compostagem (Tubail et al., 2008).

Segundo a legislação brasileira (Brasil, 2005; 2006), para que um composto orgânico possa ser comercializado como fertilizante ele deve apresentar, no mínimo, $15 \%$ de carbono (C) orgânico, $1 \%$ de nitrogênio total $(\mathrm{N}), 18: 1$ de relação $\mathrm{C}: \mathrm{N}$, 20:1 de relação CTC:C e 6,0 de valor de $\mathrm{pH}$, além de limite máximo de umidade (50\%) e de baixa contaminação com parasitos, indicadores de micro-organismos enteropatogênicos e metais tóxicos. Esta exigência legal visa estabelecer um padrão de qualidade de compostos orgânicos tendo em vista a preservação ambiental e a eficiência agronômica desses materiais (Higarashi et al., 2008; Daza-Torres et al., 2008).

Assim, os processos de tratamento de resíduos orgânicos utilizados como fertilizantes devem ser avaliados com tais critérios; adicionalmente, o aumento da concentração do N em estercos facilita a sua comercialização agrícola e, tradicio- nalmente, a perda deste nutriente tem sido amenizada com a adição de materiais ricos em carbono, nas pilhas de compostagem (Martins \& Dewes, 1992; Kiehl, 2002). No entanto, o preço elevado, além da baixa disponibilidade desses materiais em determinados locais, como ocorre, por exemplo, com a maravalha, pode inviabilizar esta alternativa. Tal aspecto é mais preocupante principalmente quando o esterco é gerado em quantidades elevadas, como se verifica nas grandes indústrias de produção de ovos.

Por outro lado, a adição do gesso tem sido proposta para amenizar a perda de $\mathrm{N}$ na compostagem de estercos (Tubail et al., 2008). Vários autores constataram que o gesso decresce em até $39 \%$ as perdas do $\mathrm{N}$ amoniacal volatilizado em cama de aviários (Glória et al., 1991; Neme et al., 2000; Prochnow et al., 2001; Oliveira et al., 2003). Este efeito é atribuído à menor volatilização do $\mathrm{N}$, na forma de $\mathrm{NH}_{3}$, uma vez que o sulfato do gesso pode combinar com o N, na forma de $\mathrm{NH}_{4}$, resultante da decomposição do $\mathrm{N}$ orgânico, decrescendo a formação de $\mathrm{NH}_{3}$ (Prochnow et al., 2001); no entanto, o efeito do gesso em pilhas de compostagem de esterco de ave poedeira ainda não é conhecido.

Embora os efeitos benéficos da aeração de pilhas de compostagem sobre a qualidade sanitária do composto sejam reconhecidos, em geral este material é disposto em monte nas propriedades agrícolas, não sendo revolvido até o momento da aplicação no solo; esta forma de armazenamento do esterco pode durar cerca de dois a quatro meses após o recebimento da carga remetida pela indústria de ovos, haja vista que o esterco é aplicado ao solo de acordo com a disponibilidade de área, para a formação da lavoura da atual estação do ano, casos em que o não revolvimento das pilhas de esterco tem sido justificado por razões operacionais (economia de óleo diesel, tempo de máquina e de pessoal) e técnicas, ainda não investigadas pela pesquisa (menor perda de $\mathrm{N}$ do esterco e efeito de atenuação do solo sobre os impactos da aplicação in natura, deste material).

Objetivou-se neste trabalho avaliar o efeito do revolvimento e da adição de gesso em pilhas de compostagem de esterco de ave poedeira na qualidade do composto obtido.

\section{MATERIAL E MÉTODOS}

O experimento foi conduzido no Campo Experimental da Faculdade de Agronomia e Medicina Veterinária da UPF, em Passo Fundo, RS, a uma altitude média de $68,7 \mathrm{~m}$ sobre o nível do mar. A precipitação pluvial média neste município é de 1.788 $\mathrm{mm}$ e a temperatura média é de $17,5^{\circ} \mathrm{C}$. O clima, segundo a classificação de Köppen, é do tipo predominante temperado (C), úmido (f), variando a subtropical (Cfa).

$\mathrm{O}$ esterco utilizado, gerado por aves poedeiras da raça $\mathrm{Hy}-$ line e criadas em sistema de confinamento, foi armazenado durante cinco dias em esteiras coletoras, dentro do aviário, antes do transporte até a UPF. As pilhas sem gesso foram montadas com sete dias de antecedência em relação às pilhas com gesso, sendo este aditivo misturado ao esterco na esteira de coleta do resíduo, visto que o período foi necessário para reunir a quantidade de esterco a ser utilizada a fim de 
formar as pilhas de compostagem; assim, dois "lotes" de esterco do mesmo aviário, foram utilizados, sendo um correspondente ao esterco sem gesso e o outro, ao esterco com gesso. Em função dessa diferença o número de dias de compostagem das pilhas foi uniformizado quando da comparação dos tratamentos com e sem gesso.

Os fatores avaliados neste experimento foram o revolvimento e a adição de gesso às pilhas de compostagem, sendo os resultados dos compostos comparados com o do esterco. Os tratamentos seguintes foram testados com três repetições: 1) sem gesso e sem revolvimento; 2) com gesso e sem revolvimento; 3) com gesso e com revolvimento e 4) sem gesso e com revolvimento; as dimensões iniciais das pilhas de compostagem foram: altura, 1,5 m; largura, $2 \mathrm{~m}$ e comprimento, 3 $\mathrm{m}$; o espaçamento entre pilhas foi de $5 \mathrm{~m}$; nas pilhas dos tratamentos 3 e 4 o revolvimento foi efetuado com retroescavadeira, com frequência semanal nas duas primeiras semanas e após efetuado três vezes por semana, até a temperatura das pilhas atingir $30{ }^{\circ} \mathrm{C}$, indicando o fim do processo de compostagem. A temperatura das pilhas foi medida a cada três dias, com termômetro digital $\left(100^{\circ} \mathrm{C}\right.$, com variação de $0,1^{\circ} \mathrm{C}$, para mais ou para menos); a haste de metal (sensor) do termômetro foi inserida até a profundidade de $0,6 \mathrm{~m}$, em 3 pontos, no sentido perpendicular ao eixo vertical das pilhas.

Para a análise de parasitas (ovos e larvas de helmintos), de metais tóxicos $(\mathrm{Cd}, \mathrm{Cr}, \mathrm{Ni}, \mathrm{Pb})$ e $\mathrm{Se}$ e dos atributos físicoquímicos (C, N, C:N, CTC, C:CTC e umidade), uma amostra de $0,5 \mathrm{dm}^{-3}$ foi coletada nas pilhas de cada tratamento e analisada em laboratório. As amostras das pilhas foram retiradas em três pontos, ou seja, na profundidade de $0,6 \mathrm{~m}$, com pá de corte, sendo homogeneizadas e acondicionadas em sacos plásticos. Para a análise dos micro-organismos enteropatogênicos (Salmonella sp, coliformes totais e fecais), utilizaramse sacos plásticos esterilizados, cuja amostra foi obtida com a mistura dos compostos coletados nos dois tratamentos com revolvimento; já os tratamentos sem revolvimento foram excluídos pois não houve decomposição nem humificação do esterco durante o período do experimento, nesses tratamentos; além disso, a temperatura nas pilhas dos tratamentos sem revolvimento não atingiu a fase termófila.

Para as análises físico-químicas e dos metais tóxicos uma amostra de 2,0 $\mathrm{dm}^{-3}$ de esterco, composta de cinco subamostras, foi coletada logo após que este material foi descarregado na área experimental. Uma alíquota desta amostra foi digerida em meio ácido, para a extração de $\mathrm{N}$ enquanto outra alíquota foi utilizada para a determinação de $\mathrm{C}$ orgânico (Método de Walkley-Black, com aquecimento externo), conforme Tedesco et al. (1995). Os atributos físico-químicos analisados no esterco e nos compostos foram os utilizados pelo Ministério de Agricultura do Brasil (MAPA), para caracterizar a qualidade agronômica de fertilizantes orgânicos (Brasil, 2006; 2007).

Ao término do período de compostagem amostras de composto foram secadas a $65^{\circ} \mathrm{C}$ em estufa com circulação de ar, até peso constante, moídas e tamisados (malha com abertura de $2 \mathrm{~mm}$ ), para as análises de metais tóxicos, Se e dos atributos físico- químicos, em duplicata. Efetuou-se a extração dos metais $\mathrm{Cd}, \mathrm{Cr}, \mathrm{Ni}, \mathrm{Pb}$ e de $\mathrm{Se}$ digerindo as amostras com áci- do nítrico em chapa aquecida (USEPA, 1996). A quantificação desses metais foi efetuada com espectrometria de emissão ótica por plasma induzido. Os teores de C, N, CTC e de água e os valores de $\mathrm{pH}$ e das relações $\mathrm{C}: \mathrm{N}$ e $\mathrm{C}$ :CTC foram determinados conforme Brasil (2007).

Os ovos viáveis de helmintos e as larvas de parasitas foram avaliados em $4 \mathrm{~g}$ de amostra úmida utilizando-se o método de Willis Mollay e Barmann, respectivamente. Efetuou-se a mensuração de coliformes totais e dos termotolerantes com o método dos tubos múltiplos, determinando-se o número mais provável (NMP). A diluição inicial utilizada foi de 1:10, sendo efetuada em $10 \mathrm{~g}$ de amostra úmida, diluída em $90 \mathrm{~mL}$ de água peptonada a $0,1 \%$. As diluições subsequentes utilizadas foram até $10^{-5}$, empregando-se cinco tubos por diluição (Eaton et al., 2005). A determinação de Salmonella sp. baseouse em metodogia de Downes \& Ito (2001); para tanto pesouse uma alíquota de $10 \mathrm{~g}$ de amostra úmida, homogeneizada com $90 \mathrm{~mL}$ de água peptonada a $1 \%$ e incubada a $36 \pm 1$ ÚC durante 18 a 24 h. Após o pré- enriquecimento a amostra foi inoculada em caldos seletivos, repicada para ágares seletivos e diferenciais e as colônias compatíveis foram confirmadas com testes bioquímicos e provas sorológicas.

Os resultados obtidos foram comparados com o padrão exigido para fertilizantes orgânicos, conforme as Instruções Normativas 23/2005 e 27/2006, do MAPA (Brasil, 2005; 2006, respectivamente), sendo as médias dos tratamentos comparadas com o teste $\mathrm{T}$ de Student, a nível de 5\% de probabilidade do erro. Efetuaram-se a análise de variância e o teste de $\mathrm{T}$, através dos programas computacionais SAS System $@$, release 6.11 e Microsoft Excel(C).

\section{RESULTADOS E DISCUSSÃO}

Verificou-se, em todos os tratamentos testados, ausência de larvas de helmintos nos compostos obtidos (Tabela 1), embora a quantidade desses organismos no esterco fosse equivalente a uma larva por $4 \mathrm{~g}$ de matéria seca. Os resultados da Tabela 1 mostram que o número de ovos desse parasita foi inexpressivo, exceto na amostra do tratamento sem revolvimento e sem a adição de gesso; neste último, o número de ovos de helmintos equivaleu a três por $4 \mathrm{~g}$ de matéria seca maior, portanto, que a quantidade máxima permitida pelo MAPA, que é de um ovo por $4 \mathrm{~g}$ de matéria seca; já nos outros tratamentos testados o número de ovos de helmintos foi menor que o máximo permitido (Brasil, 2006).

Tabela 1. 0 corrência de ovos viáveis e de larvas de helmintos em composto de esterco de ave poedeira, obtidos com diferentes tratamentos de compostagem

\begin{tabular}{lccc}
\hline Tratamento & Sólidos totais (\%) & Ovos & Larvas \\
1. Sem gesso e sem revolvimento & 64,2 & $3 \mathrm{~b}$ & Ausente \\
2. Com gesso e sem revolvimento & 62,0 & $1 \mathrm{a}$ & Ausente \\
3. Sem gesso e com revolvimento & 75,0 & $1 \mathrm{a}$ & Ausente \\
4. Com gesso e com revolvimento & 72,5 & $1 \mathrm{a}$ & Ausente \\
\hline
\end{tabular}

Médias seguidas de mesma letra, na coluna, não diferem entre si pelo teste de Student, a $5 \%$ de probabilidade do erro. ${ }^{\text {ns: }}$ não significativo, na linha; * (quantidade em $4 \mathrm{~g}$ de matéria úmida) 
A ausência de larvas de helmintos e, em geral, de ovos desse parasito, observada nos compostos avaliados se deve, possivelmente, aos baixos valores desses organismos no esterco avaliado (Santos, 2008). Além disso, se observaram, nas pilhas revolvidas, valores de temperatura próximos a $60{ }^{\circ} \mathrm{C}$ (Figura 1A), associados à destruição de helmintos (Matos et al., 1998; Tiquia \& Tam, 2000). Soccol et al. (1997) e Corrêa et. al. (2007) também relatam alta taxa de redução (entre 93 e 100\%) do número de ovos de helmintos avaliados em amostras de lodo de esgoto compostado; desta forma, o resultado obtido na amostra do tratamento sem revolvimento e sem adição de gesso, deve ser interpretado com cautela visto que pode ser resultante de alguma falha no procedimento de amostragem ou do revolvimento, representando as camadas externas da pilha.

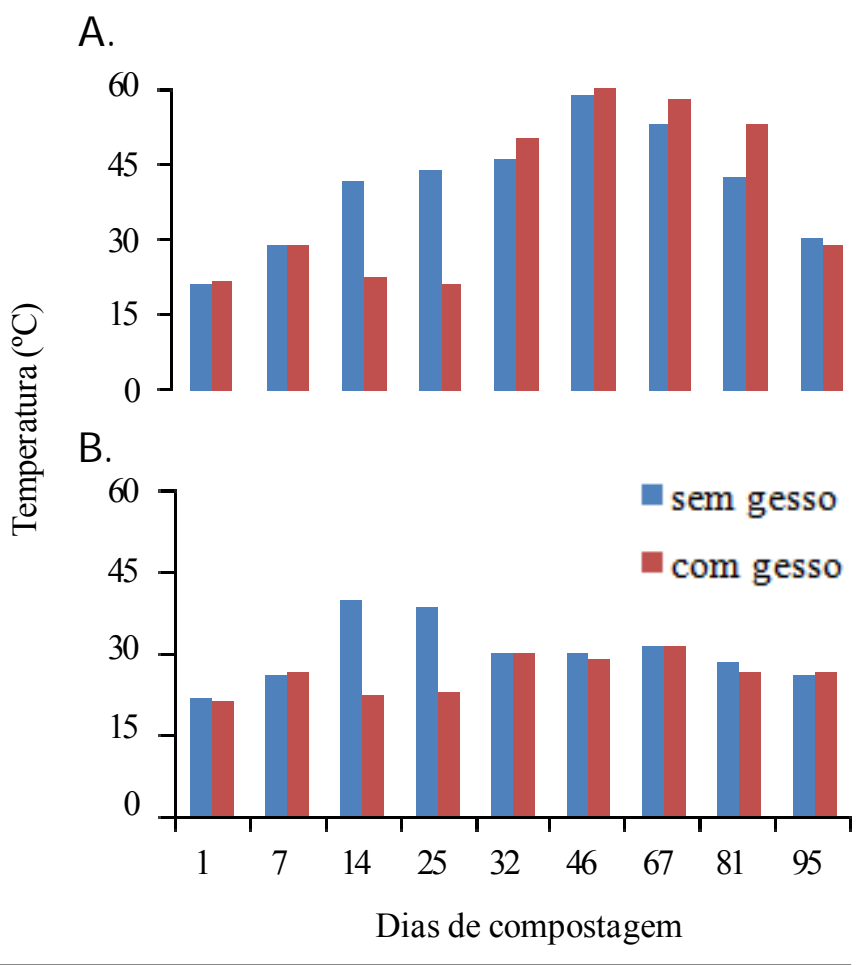

Figura 1. Temperatura em pilhas de esterco de ave poedeira, em função do tempo de compostagem e da adição de gesso. (A) pilhas revolvidas e (B) pilhas não revolvidas

Nota-se, comparando-se os resultados dos Tratamentos 1 e 2, que a adição de gesso nas pilhas sem revolvimento reduziu expressivamente o número de ovos viáveis de helmintos. Este efeito pode estar relacionado à menor perda de nitrogênio e ao maior teor deste elemento na forma amoniacal e/ou ao maior teor de sais solúveis na pilha de compostagem, decorrente da adição do gesso. Santos et al. (2000) relatam que este aditivo pode diminuir o número de larvas de mosca, em cama de esterco de ovino, sugerindo que tal efeito se deva ao acréscimo da concentração de amônio e de sais diversos. Da mesma forma, Sampaio et al. (1999) constataram decréscimo na contagem padrão de micro-organismos avaliando a população microbiana em cama de aviário tratada com gesso agrícola.
Conforme a Instrução Normativa $n^{\circ}$ 27/2006, do Ministério da Agricultura, Pecuária e Abastecimento do governo brasileiro (MAPA), além da ocorrência de parasitos outros organismos, como bactérias enteropatogênicas, devem ser monitorados, com vistas a assegurar que a população presente não seja maior que o padrão estipulado para os fertilizantes orgânicos obtidos de esterco animal (Brasil, 2006). Verificou-se, neste trabalho, ausência de Salmonella sp, tanto no esterco como nos compostos (Tabela 2).

Tabela 2. Ocorrência de enteropatogênicos, antes e após a compostagem de esterco de ave poedeira. Média dos tratamentos com revolvimento

\begin{tabular}{cccc}
\hline Enteropatogênico & $\begin{array}{c}\text { Antes da } \\
\text { compostagem }\end{array}$ & $\begin{array}{c}\text { Após a } \\
\text { compostagem }\end{array}$ & $\begin{array}{c}\text { Valor máximo } \\
\text { permitido para } \\
\text { fertilizantes orgânicos }\end{array}$ \\
$\begin{array}{c}\text { Coliformes totais (NMP g-1) } \\
\text { Coliformes termotolerantes } \\
(\text { NMP g-1) }\end{array}$ & $1,7 \times 10^{6}$ & $<1,0 \times 10^{-1}$ & - \\
$\begin{array}{c}\text { Salmonella sp } \\
\text { (pesquisa em 10 g) }\end{array}$ & Ausencia & Ausência & Ausência \\
\hline
\end{tabular}

${ }^{1}$ Instrução Normativa $n^{\circ}$ 27/2006 (Brasil, 2006). Resultados expressos em base úmida

Os resultados desta tabela também mostram que os NMPs de coliformes totais e termotolerantes no esterco de ave poedeira $\left(1,7 \times 10^{6} \mathrm{NMP} \mathrm{g}^{-1}\right.$, respectivamente), decresceram significativamente com a compostagem, sendo os valores obtidos nos compostos menores que 1,0 x $10^{1} \mathrm{NMP} \mathrm{g}^{-1}$. Referidos valores de NMP observados nos compostos foram menores que o máximo admitido pelo MAPA $\left(1,0 \times 10^{3} \mathrm{NMP} \mathrm{g}^{-1}\right.$; Brasil, 2006); então, os resultados indicam que a compostagem foi eficiente em decrescer a população de coliformes do esterco, possibilitando o uso deste material como fertilizante agrícola, sem risco de contaminar o solo com bactérias enteropatogênicas.

A destruição de micro-organismos patogênicos tem sido observada na compostagem de vários resíduos orgânicos, como o lodo de curtume (Araújo et al., 2008); resíduos sólidos domiciliares (Escosteguy et al., 1993) e estercos de animais (Tiquia \& Tam, 2000). A destruição desses micro-organismos no processo de compostagem ocorre sobretudo em temperaturas maiores que $55^{\circ} \mathrm{C}$ (Hassen et al., 2001). Assim, é provável que a destruição dos coliformes avaliados neste trabalho se deva aos valores de temperatura observados nas pilhas revolvidas, os quais foram cerca de $55^{\circ} \mathrm{C}$, aos 46 dias de compostagem e maiores que este valor a partir deste período (Figura 1A). Os resultados apresentados nesta Figura também indicam que a adição de gesso às pilhas de compostagem não comprometeu a destruição dos organismos, visto que o aditivo não impediu a elevação da temperatura a partir do $46^{\circ}$ dia de compostagem.

Os valores de $\mathrm{Cd}, \mathrm{Cr}$ e $\mathrm{Se}$ obtidos nas amostras dos compostos analisados diferiram entre os tratamentos testados mas isto não foi observado com os teores de $\mathrm{Ni}$ e $\mathrm{Pb}$ (Tabela 3). $\mathrm{O}$ teor de $\mathrm{Cd}$ foi maior $(\mathrm{p}=0,0086)$ nos compostos das pilhas sem gesso, independente do fator revolvimento. Este efeito também foi observado com os teores de $\mathrm{Cr}$ e de Se, mas somente nos compostos das pilhas revolvidas $(p=0,0286$ e 
Tabela 3. Teor de elementos tóxicos em esterco de ave poedeira e em compostos obtidos com diferentes tratamentos de compostagem

\begin{tabular}{|c|c|c|c|c|c|c|c|}
\hline \multirow{3}{*}{ Metal ${ }^{1}$} & \multicolumn{6}{|c|}{ Gesso } & \multirow{3}{*}{$\begin{array}{l}\text { Valor } \\
\text { máximo } \\
\text { admitido }\end{array}$} \\
\hline & \multicolumn{2}{|c|}{ Esterco } & \multicolumn{2}{|c|}{ Revolvidas } & \multicolumn{2}{|c|}{ Não Revolvidas } & \\
\hline & com & sem & com & sem & com & sem & \\
\hline Cádmio & 1,5 & 3,1 & $2,3 \mathrm{~b}$ & $3,5 \mathrm{a}$ & $2,7 \mathrm{~b}$ & $3,6 \mathrm{a}$ & 3,0 \\
\hline Selênio & - & - & $56,6 \mathrm{a}$ & 53,3 a & $70,0 \mathrm{a}$ & $36,6 \mathrm{~b}$ & 80,0 \\
\hline Cromo & 8,0 & 1,6 & $134,2 \mathrm{a}$ & $89,5 \mathrm{a}$ & $68,3 b$ & $105,9 a$ & 200,0 \\
\hline Níquel & 5,6 & 12,6 & $29,5 \mathrm{~ns}$ & 28,3 & 26,2 & 29,5 & 70,0 \\
\hline Chumbo & 9,7 & 28,9 & $41,6 \mathrm{~ns}$ & 44,8 & 41,6 & 40,0 & 150,0 \\
\hline
\end{tabular}

1: Valores expressos em base seca, umidade determinada a $65{ }^{\circ} \mathrm{C} .{ }^{2}$ : Instrução Normativa N²7/2006 (Brasil, 2006). Médias seguidas da mesma letra, na linha, não diferem entre si pelo teste de Student, a 5\% de probabilidade do erro. ${ }^{\text {ns: }}$ não significativo, na linha

0,0097, respectivamente). Os teores dos metais analisados foram menores que os teores máximos tolerados pelo MAPA, exceto o de $\mathrm{Cd}$, nos compostos das pilhas sem gesso. Nessas amostras os teores desse metal corresponderam a 3,47 e $3,57 \mathrm{mg} \mathrm{kg}^{-1}$, excedendo em cerca de $20 \%$ o teor máximo de 3,0 mg Cd kg-1 tolerado para fertilizantes orgânicos (Brasil, 2006). Conforme os resultados da Tabela 3, o teor de Cd do lote de esterco utilizado para confeccionar as pilhas com gesso foi cerca da metade $\left(1,5 \mathrm{mg} \mathrm{kg}^{-1}\right)$ do teor do lote utilizado para montar as pilhas sem gesso $\left(3,1 \mathrm{mg} \mathrm{kg}^{-1}\right)$; desta forma, as diferenças entre os teores de $\mathrm{Cd}$ verificadas entre os compostos com e sem gesso são devidas às características intrínsecas do lote de esterco utilizado para confeccionar as pilhas de compostagem não sendo, entretanto, um efeito causado por este aditivo.

Os teores de $\mathrm{Cd}\left(2,3\right.$ a 3,6 mg kg-1), $\mathrm{Cr}\left(68,3\right.$ a $134,0 \mathrm{mg} \mathrm{kg}^{-}$ 1), Ni (26,2 a 29,5 mg kg-1) e Pb (40,0 a 44,8 $\left.\mathrm{mg} \mathrm{kg}^{-1}\right)$, obtidos nos compostos, foram expressivamente maiores que os teores médios obtidos nos estercos utilizados $(2,3 ; 4,8 ; 9,1$ e 19,3 $\mathrm{mg} \mathrm{kg}^{-1}$, respectivamente) (Tabela 3$)$. Este acréscimo de metais pode estar relacionado com o decréscimo do teor de $\mathrm{C}$ resultante da decomposição e da mineralização dos compostos orgânicos do esterco, além de outros compostos voláteis, como o $\mathrm{N}$ e o $\mathrm{S}$, o que proporciona o acréscimo da concentração de elementos não voláteis na matéria seca das amostras, como os metais analisados neste trabalho. A redução de elementos voláteis, durante a compostagem, pode ser inferida a partir dos resultados da Tabela 4 , que mostram que os teores de $\mathrm{C}$ e de $\mathrm{N}$ variaram de 25,2 e $6,9 \%$, respectivamente, no esterco com gesso; a 6,1 e $1,4 \%$, respectivamente, nos compostos obtidos com o revolvimento das pilhas, decrescendo aproximadamente 76 e $80 \%$, respectivamente, com a compostagem. Nas pilhas sem gesso os teores de $\mathrm{C}$ e de $\mathrm{N}$ variaram de 23,1 e 7,0\%, respectivamente, no esterco sem gesso; a 7,7 e 1,0\%, respectivamente, nos compostos das pilhas revolvidas, decrescendo aproximadamente 66 e $86 \%$.

Os efeitos da volatilização de $\mathrm{C}$ na forma de $\mathrm{CO}_{2}$, e de $\mathrm{N}$, na forma de $\mathrm{NH}_{3}$, sobre a concentração de metais na matéria seca do esterco compostado, também podem estar relacionados com os maiores teores de metais, incluindo o $\mathrm{Cd}$, obtidos nos compostos das pilhas sem gesso. A relação $\mathrm{C}: \mathrm{N}$ do esterco utilizado nesses tratamentos foi de 2,8 , expressivamen-
Tabela 4. Teor de carbono orgânico $(C)$ e nitrogênio total $(N)$, relação $C: N$, capacidade de troca de cátions $(C T C)$, relação CTC:C, valor do pH em água e de umidade (Ug) em compostos de esterco de ave poedeira, obtidos com diferentes tratamentos de compostagem

\begin{tabular}{|c|c|c|c|c|c|c|c|}
\hline \multirow{2}{*}{ Atributo $^{1}$} & \multicolumn{2}{|c|}{ Esterco } & \multicolumn{2}{|c|}{ Revolvidas } & \multicolumn{2}{|c|}{ Não Revolvidas } & \multirow{2}{*}{$\begin{array}{c}\text { Valor máximo } \\
\text { admitido }^{1}\end{array}$} \\
\hline & com & sem & com & sem & com & sem & \\
\hline C (\%) & 25,2 & 23,1 & $7,7 \mathrm{bc}$ & $6,1 \mathrm{c}$ & $9,4 \mathrm{~b}$ & $16,4 \mathrm{a}$ & $\geq 15,0$ \\
\hline N (\%) & 6,9 & 7,0 & $1,4 \mathrm{~b}$ & $1,0 \mathrm{~b}$ & $3,1 \mathrm{a}$ & $0,6 c$ & $\geq 1,0$ \\
\hline $\mathrm{C}: \mathrm{N}$ & 4,3 & 2,8 & $5,5 b$ & $6,1 \mathrm{~b}$ & $3,0 \mathrm{~b}$ & $26,7 a$ & $\leq 18: 1$ \\
\hline CTC $\left(\mathrm{mmol} \mathrm{kg}^{-1}\right.$ & ) 110,0 & 101,2 & 135,4 & 143,7 & 119,7 & 127,0 & Conforme declarado \\
\hline CTC:C & 4,4 & 4,4 & 27,9 & 39,0 & 41,3 & 27,5 & $\geq 20: 1$ \\
\hline $\mathrm{pH}(\mathrm{H} 2 \mathrm{O})$ & 8,8 & 7,9 & $7,2 \mathrm{C}$ & $8,2 a b$ & $8,3 b$ & $8,6 \mathrm{a}$ & $\geq 6,0$ \\
\hline Ug (\%) & 64,4 & 66,4 & $37,7 \mathrm{~b}$ & $33,1 \mathrm{~b}$ & $61,1 \mathrm{a}$ & $55,7 a$ & $\leq 50,0$ \\
\hline
\end{tabular}

te menor que a do esterco utilizado nos tratamentos com gesso $(\mathrm{C}: \mathrm{N}=4,3)$ (Tabela 4). A menor $\mathrm{C}: \mathrm{N}$ do esterco sem gesso pode ter favorecido os processos de amonificação e de volatilização do $\mathrm{N}$, decrescendo o teor deste elemento e concentrando, portanto, os teores dos metais analisados.

Os resultados da Tabela 4 indicam que o teor inicial de $\mathrm{C}$ do esterco foi cerca de $24 \%$ situando-se na faixa relatada para esterco de outros animais. Por outro lado, o teor de $\mathrm{N}$ total desse resíduo foi cerca de $7 \%$ maior, portanto, que o geralmente observado em outros estercos (Kiehl, 2002). Como consequência do alto teor de $\mathrm{N}$, a relação $\mathrm{C}: \mathrm{N}$ do esterco foi baixa (cerca de $3,5 \%$ ), contribuindo para a perda de $\mathrm{N}$ no processo de compostagem. Assim, os teores de $\mathrm{N}$ total obtidos nos compostos avaliados foram baixos (média de 1,2 e de $1,4 \%$, com e sem revolvimento das pilhas, respectivamente). Esta perda de $\mathrm{N}$ na compostagem tem sido observada em outros trabalhos e se deve à volatilização desse nutriente na forma de amônia. Como a volatilização aumenta com o valor de $\mathrm{pH}$ e da umidade e com o menor valor da C:N (Kiehl, 2002; Prochnow et al., 2001), os baixos teores de $\mathrm{N}$ observados nos compostos estão de acordo com os valores desses atributos do esterco utilizado neste trabalho (Tabela 4).

Em geral, os teores de $\mathrm{C}$ obtidos nos compostos analisados foram menores que o mínimo de $15 \%$ exigido pelo MAPA (Brasil, 2006), exceto nos compostos das pilhas sem gesso e não revolvidas (Tabela 4). Neste tratamento o teor de $\mathrm{C}$ foi de $16,4 \%$, isto é, superior aos obtidos nos demais tratamentos. $\mathrm{O}$ decréscimo da maior parte do $\mathrm{C}$ na compostagem é inerente a tal processo, pois se deve, principalmente, à liberação de $\mathrm{CO}_{2}$, resultante da respiração dos micro-organismos responsáveis pela transformação da matéria orgânica em húmus (Kiehl, 2002). Como tal atividade aumenta com o acréscimo de oxigênio nas pilhas de compostagem, é provável que a redução da frequência do revolvimento das pilhas e, consequentemente, do decréscimo da taxa de aeração, possa amenizar as perdas de $\mathrm{C}$ dos compostos atendendo ao padrão do MAPA.

Associado à menor frequência de revolvimento é possível amenizar os baixos teores de $\mathrm{C}$ dos compostos com o menor 
tempo de compostagem. No presente trabalho este material foi compostado durante 95 dias; no entanto, os maiores valores de temperatura das pilhas foram observados entre os 46 e 67 dias de compostagem (Figura 1). Considerando-se que este período seja o mais importante para a destruição dos organismos patogênicos, o tempo de compostagem poderia ser abreviado em cerca de 30 dias; recomenda-se, então, avaliar os teores de $\mathrm{C}$ das pilhas nesta época e, se eles fossem maiores que $15 \%$, os demais indicadores de qualidade exigidos pelo MAPA deveriam ser reavaliados para confirmar a possibilidade de se reduzir o tempo de compostagem e aumentar o teor de $\mathrm{C}$ dos compostos.

Os teores de $\mathrm{N}$ obtidos com os tratamentos testados foram, em geral, maiores que $1 \%$, atendendo ao mínimo tolerado (Tabela 4); entretanto, nos composto das pilhas sem gesso e não revolvidas, ao contrário do verificado com o $\mathrm{C}$, o teor de $\mathrm{N}$ foi baixo $(0,6 \%)$, isto é, menor que o mínimo exigido; em virtude do evento, a relação $\mathrm{C}: \mathrm{N}$ desses compostos foi de 26,7, maior que o máximo tolerado pelo MAPA (18:1) (Tabela 4); desta forma, a adição de gesso nas pilhas não revolvidas propiciou a obtenção de compostos com teores de $\mathrm{C}$ e de $\mathrm{N}$, de acordo com os valores tolerados; além disso, o efeito deste aditivo possibilitou maiores teores de $\mathrm{N}$ nos compostos $(3,1 \%$ contra $0,6 \%)$ tendência esta observada nos compostos das pilhas revolvidas $(1,4 \%$ contra $1,0 \%)$, cuja diferença não foi confirmada pela análise estatística (Tabela 4).

Semelhante ao observado com o $\mathrm{C}$, o $\mathrm{N}$ e a $\mathrm{C}: \mathrm{N}$, os valores da relação $\mathrm{CTC}$ : $\mathrm{C}$ e de $\mathrm{pH}$, atenderam ao padrão do MAPA, em todos os tratamentos testados (Tabela 4). Os resultados desta tabela também apontam que o gesso decresceu o valor do $\mathrm{pH}$ dos compostos, cujo efeito foi mais expressivo nas pilhas revolvidas mas, no $\mathrm{pH}$ e o causado nos teores de $\mathrm{N}$, indicam que a adição deste resíduo da construção civil em pilhas de compostagem de esterco de ave poedeira, decresce as perdas de $\mathrm{N}$ que ocorrem durante o processo.

Por outro lado, o teor de umidade dos compostos obtidos nas pilhas não revolvidas excedeu o máximo tolerado pelo MAPA (50\%), independente da adição de gesso enquanto nos compostos revolvidos o teor de umidade foi menor que o máximo tolerado por este órgão (Tabela 4). Referidos resultados estão de acordo com os valores de temperatura observados nesses tratamentos, conforme já discutido (Figura 1).

Os resultados deste trabalho indicam que nenhum dos tratamentos testados possibilitou a obtenção de compostos que atendessem a todos os padrões de qualidade avaliados. Os compostos das pilhas revolvidas podem ser considerados de melhor qualidade, pois a única restrição observada foi o menor teor de C em relação ao exigido pelo MAPA. Tal limitação pode ser evitada de várias maneiras, como o decréscimo do teor de proteínas na ração das aves, o acréscimo de material rico em $\mathrm{C}$ ao esterco ou, simplesmente, controlando-se o tempo de compostagem e a frequência do revolvimento, em função do teor de C das pilhas; conclui-se, então, que os compostos obtidos nas pilhas não revolvidas apresentaram restrição sanitária (ovos de helmintos) e físico-química (baixo teor de N), sendo, portanto, de menor qualidade.

\section{CONCLUSÕES}

1.Em geral, a melhor qualidade dos compostos de esterco de ave poedeira foi obtida com o revolvimento das pilhas de compostagem.

2.Os teores de $\mathrm{N}$ e de umidade e o número de ovos de helmintos dos compostos obtidos em pilhas não revolvidas não atendem aos padrões do MAPA.

3.Comumente, os teores de metais tóxicos e de Se dos compostos foram menores que o máximo tolerado pelo MAPA.

4.A adição de gesso às pilhas de compostagem decresce o valor do $\mathrm{pH}$ dos compostos e, nas pilhas não revolvidas, este aditivo aumenta o teor de $\mathrm{N}$.

5.A ocorrência de larvas de helmintos e de bactérias Salmonella $s p$. não foi detectada nos compostos dos tratamentos testados, o que também ocorreu com os coliformes fecais e totais, nos compostos das pilhas revolvidas.

\section{LITERATURA CITADA}

Araújo, F. F. de; Tiritan, C. S.; Pereira, H. M.; Caetano Júnior. O. Desenvolvimento do milho e fertilidade do solo após aplicação de lodo de curtume e fosforita. Revista Brasileira de Engenharia Agrícola e Ambiental, v.12, n.5, p.507-511, 2008.

Brasil. Ministério da Agricultura, Pecuária e Abastecimento. Instrução Normativa n· 23, de 31 de agosto de 2005. Diário Oficial da República Federativa do Brasil, Brasília, DF, 08 de dezembro de 2005. Seção 1, p.12.

Brasil. Ministério da Agricultura, Pecuária e Abastecimento. Instrução Normativa $n^{\circ} 27$, de 05 de junho de 2006. Diário Oficial da República Federativa do Brasil, Brasília, DF, 09 de junho de 2006. Seção 1, p.15.

Brasil. Ministério da Agricultura, Pecuária e Abastecimento. Instrução Normativa $n^{\circ} 28$, de 27 de julho de 2007. Diário Oficial da República Federativa do Brasil, Brasília, DF, 31 de julho de 2007. Seção 1, p.11.

Brasil. Ministério da Agricultura, Pecuária e Abastecimento. Instrução Normativa $n^{0}$ 64, de 18 de dezembro de 2008. Diário Oficial da República Federativa do Brasil, Brasília, DF, 19 de dezembro de 2008. Seção 1, p.21.

Ceretta, C. A.; Durigon, R; Basso, C. J.; Barcellos, L. A. R.; Vieira, F. C. B. Características químicas de solo sob aplicação de esterco líquido de suínos em pastagem natural. Pesquisa Agropecuária Brasileira, v.38, n.6, p.729-735, 2003.

Corrêa, É. K.; Thomaz Júnior, L.; Gil-Turnes, C.; Corrêa, M. N.; Bianchi, I.; Corezzolla, J. L.; Ulguim, R. R. Efeito de diferentes profundidades de cama sobre parâmetros ambientais para suínos em crescimento e terminação. Revista Brasileira de Engenharia Agrícola e Ambiental, v.12, n.5, p.540-545, 2008.

Corrêa, R. S.; Fonseca. Y. M. F.; Corrêa, A. S. Produção de biossólido agrícola por meio da compostagem e verminocompostagem de lodo de esgoto. Revista Brasileira de Engenharia Agrícola e Ambiental, v.11, n.4, p.420-426, 2007.

Daza-Torres, M. C.; Alvarez-Herrera, J. G.; Camacho-Tamayo, J. H. Aplicación de materiales orgánicos e inorgánicos en la adsorción de fósforo en un Oxisol. Revista Brasileira de Engenharia Agrícola e Ambiental, v.12, n.5, p.451-457, 2008. 
Downes, F .P.; Ito, K. Compendium of methods for the microbiological examination of foods. 4.ed. Washington: APHA, 2001. 676p.

Eaton, A. D.; Clesceri, L. S.; Rice, E. W.; Greenberg, A. E. Standard methods for the examination of water and wastewater. 21.ed. Maryland: APHA, 2005. 1325p.

Endale, D. M.; Shomberg, H. H.; Fisher, D. S.; Jenkins, M. B.; Sharpe, R. R.; Cabrera, M. L. No-till corn productivity in a Southeastern United States ultisol amended with poultry litter. Agronomy Journal, v.10, n.5, p.1401-1408, 2008.

Escosteguy, P. A. V.; Parchen, C. A. P.; Selbach, P. A. Bactérias enteropatogênicas em composto de lixo domiciliar, solo e planta. Revista Brasileira de Ciência do Solo, v.17, n.3, p.365369, 1993.

Fernandes, F.; Souza, S. G. Estabilização de lodo de esgoto. In: Andreoli, C. V. (Org.). Resíduos sólidos do saneamento: Processamento, reciclagem e disposição final. 1.ed. Rio de Janeiro: Rima ABES, 2001. p.32-57.

Glória, N. A.; Barreto, M. C. V.; Moraes, C. J.; Mattiazzo-Prezotto, M. E. Avaliação do gesso e de alguns fosfatos como inibidores da volatilização de amônia de estercos. Revista Brasileira de Ciência do Solo, v.15, n.3, p.297-301, 1991.

Gonçalves, V. P.; Marin, J. M. Fate of non O157 Shiga toxigenic Escherichia coli in composted cattle manure. Arquivo Brasileiro de Medicina Veterinária e Zootecnia, v.59, n.4, p.825831, 2007.

Gómez, R. B.; Ferrer, A. S. The use of respiration indices in the composting process: A review. Waste Management \& Reseach, v.24, n.1, p.37-47, 2006.

Hassen, A.; Belguith, K.; Jedidi, N.; Cherif, A.;Cherif, M.; Boudabous, A. Microbial characterization during composting of municipal solid waste. Bioresource Technology, v.80, n.3, p.217-25, 2001.

Higarashi, M. M.; Coldebella, A.; Oliveira, P. A. V. de; Kunz, A.; Mattei, R. M.; Silva, V. S.; Amaral, A. L. do. Concentração de macronutrientes e metais pesados em maravalha de unidade de suínos em cama sobreposta. Revista Brasileira de Engenharia Agrícola e Ambiental, v.12, n.3, p.311-317, 2008.

Hsu, J. H.; Lo, S. L. Effect of composting on characterization and leaching of copper, manganese, and zinc from swine manure. Environmental Pollution, v.114, n.1, p.119-127, 2001.

Kiani, M. J.; Abbasi, M. K.; Rahim, N. Use of organic manure with mineral $\mathrm{N}$ fertilizer increases wheat yield at Rawalakot Azad Jammu and Kashmir. Archives of Agronomy and Soil Science, v.51, p.299-309, 2005.

Kiehl, E. J. Manual de compostagem: Maturação e qualidade do composto. 3.ed. Piracicaba: Edmar José Kiehl, 2002. 171p.

Lau, A. K.; Lo, K. V.; Liau, P. H.; Yu, J. C. Aeration experiments for swine waste composting. Bioresource Technology, v.41, n.2, p.145-152, 1992.

Lima, C. C.; Mendonça, E. S.; Silva, I. R.; Silva, L. H. M.; Roig, A. Caracterização química de resíduos da produção de biodiesel compostados com adição mineral. Revista Brasileira de Engenharia Agrícola e Ambiental, v.13, n.3, p.334-340, 2009.

Maragno, E. S.; Trombin, D. F.; Viana, E. O uso da serragem no processo de minicompostagem. Engenharia Sanitária e Ambiental-ABES, n.4, v.12, p.355-360, 2007. Nota Técnica
Martins, O.; Dewes, T. Loss of nitrogenous compounds during composting of animal wastes. Bioresource Technology, v.42, n.2, p.103-111, 1992.

Matos, A. T. de; Vidigal, S. M.; Sediyama, M. A. N.; Garcia, N. C. P.; Ribeiro, M. F. Compostagem de alguns resíduos orgânicos, utilizando-se águas residuárias da suinocultura como fonte de nitrogênio. Revista Brasileira de Engenharia Agrícola e Ambiental, v.2, n.2, p.199-203, 1998.

Moreng, R. E.; Avens J. S. Ciência e produção de aves. Departament of Animal Science. Fort Collins: Colorado State University. 1990.380p.

Neme, R.; Sakomura, N. K.; Oliveira, M. D. S. de; Longo, F. A.; Figueiredo, A. N. Adição de gesso agrícola em três tipos de cama de aviário na fixação de nitrogênio e no desempenho de frango de corte. Ciência Rural, v.30, n.4, p.687-692, 2000.

Oliveira M. C. de; Almeida, C. V.; Andrade, D. O.; Rodrigues, S. M. M. Teor de matéria seca, $\mathrm{pH}$ e amônia volatilizada da cama de frango tratada ou não com diferentes aditivos. Revista Brasileira de Zootecnia, v.32, n.4, p.951-954, 2003.

Palhares, J. C. P.; Calijuri, M. do C. Caracterização dos afluentes e efluentes suinícolas em sistemas de crescimento/terminação e qualificação de seu impacto ambiental. Ciência Rural, v.37, n.2, pp.502-509 2007.

Prochnow, L. I.; Cunha, C.; Kiehl, J. C.; Alcarde, J. Controle da volatilização de amônia em compostagem, mediante adição de gesso agrícola e superfosfatos com diferentes níveis de acidez residual. Revista Brasileira de Ciência do Solo, v.25, n.1, p. 65-70, 2001.

Sampaio, M. A. P. M.; Schocken-Iturrino, R. P.; Sampaio, A. A. M.; Berchielli, S. C. P.; Biondi, A. Study of the microbial population and ammonia release of treated broiler litter with agricultural gypsum. Arquivo Brasileiro de Medicina Veterinária e Zootecnia, v.51, n.6, p.559-564 1999.

Santos, F. G. Avaliação da adição de gesso e do revolvimento em pilhas de compostagem e na qualidade do composto de esterco de ave poedeira. Passo Fundo: UPF, 2008. 103p. Dissertação Mestrado

Santos, L. E.; Cunha, E. A. da; Bueno, M. S.; Verissimo, C. J. Condicionamento da cama de ovinos confinados com uso de fertilizantes fosfatados. http://www. Ovinosbrasil.com.15 Mar. 2000.

Soccol, V. T.; Paulino, R. C.; Castro, E. A.; Traz, J. Eficácia dos diferentes processos de tratamento do lodo na redução da viabilidade de ovos de helmintos. Sanare, Revista Técnica da SANEPAR, v.8, n.8, p.24-32, 1997.

Sommer, S. G.; Petersen, S. O.; Sorensen, P.; Poulsen, H. D.; Moller, H. B. Methane and carbon dioxide emissions and nitrogen turnover during liquid manure storage. Nutrient Cycling in Agroecosystems, v.78, p.27-36, 2007.

Tedesco, M. J.; Gianello, C.; Bissani, C. A.; Bohnen, H. E.; Volkweiss, S. J. Análises de solo, plantas e outros materiais. 2.ed. Porto Alegre: Universidade Federal do Rio Grande do Sul, 1995. 174p. Boletim técnico 5

Tiquia, S. M.; Tam, N. F. Y. Fate of nitrogen during composting of chicken litter. Environmental Pollution, v.110, p.535-541, 2000 . 
Tiquia, S. M.; Tam, N. F. Y.; Hodgkiss, I. J. Salmonella elimination during composting of spent pig litter. Bioresource Technology, v.63, p.193-196, 1998.

Tubail, K; Chen, L.; Michel Jr., F. C.; Keener, H. M.; Rigot, J. F.; Klingman, M.; Kost. D.; Dick, W. A. Gypsum additions reduce ammonia nitrogen losses during composting of dairy manure and biosolids. Compost Science \& Utilization, v.16, n.4, p.285-293, 2008.
UBA - União Brasileira de Avicultura. Relatório Anual 2006/ 2007. São Paulo: UBA, 2007. 82p.

USEPA - United States Environment Protection Agency. Method 3050B. 1996. 12p.

Vinnerás, B. Comparison of composting, storage and urea treatment for sanitizing of fecal matter and manure. Bioresource Technology, v.98, n.17, p.3317-3321, 2007. 